\title{
Pyrrole as an Important Scaffold of Anticancer Drugs: Recent Advances
}

\author{
Emilio Mateev ${ }^{1}$, Maya Georgieva ${ }^{1}$ and Alexander Zlatkov ${ }^{1}$ \\ ${ }^{1}$ Department of Pharmaceutical Chemistry, Faculty of Pharmacy, Medical University, Sofia, Bulgaria
}

Corresponding author: Emilio Mateev, Department of Pharmaceutical Chemistry, Faculty of Pharmacy, Medical University, Sofia, Bulgaria; TEL: +359 887490680; email: e.mateev@pharmfac.mu-sofia.bg

Received, October 16 2021; Revised, November 18, 2021; Accepted, November 30, 2021; Published, January 4, 2021

\begin{abstract}
With the significant increase of patients suffering from different types of cancer, it is evident that prompt measures in the development of novel and effective agents need to be taken. Pyrrole moiety has been found in various active compounds with anti-inflammatory, antiseptic, antibacterial, lipid-lowering and anticancer properties. Recent advances in the exploration of highly active and selective cytotoxic structures containing pyrrole motifs have shown promising data for future investigations. Accordingly, this review presents an overview of recent developments in the pyrrole derivatives as anticancer agents, with a main focus towards the key moieties required for the anti-tumor activities. Pyrrole molecules comprising prominent targeting capacities against microtubule polymerization, tyrosine kinases, cytochrome p450 family 1, histone deacetylase and bcl-2 proteins were reported. In addition, several mechanisms of action, such as apoptosis, cell cycle arrest, inhibiting kinases, angiogenesis, disruption of cell migration, modulation of nuclear receptor responsiveness and others were analyzed. Furthermore, in most of the discussed cases we provided synthesis schemes of the mentioned molecules. Overall, the utilization of pyrrole scaffold for the design and synthesis of novel anticancer drugs could be a promising approach for future investigations.
\end{abstract}

\section{INTRODUCTION}

Cancer stands as one of the greatest challenges to global health worldwide as it is ranked second for the cause of deaths worldwide (1). The steadily increasing number of patients suffering from cancer, together with the cost of therapy are the main factors which ignite the search for novel and effective chemotherapeutic agents with minimal or no toxicity to normal cells (2). Genetic disorders caused by heritance or inheritance factors have a major role in the initiation and development of mutations in the human genes (3). Overall, cancer affects the function of vital genes while causing cell cycle arrest and therefore abnormal cell proliferation, with a subsequent conversion of proto-oncogenes to oncogenes (4). Among the widespread types of cancers are breast cancer, prostate cancer, colon cancer, lung cancer, colon and rectum cancer, and bladder cancer. Breast and prostate cancers are the most common types of tumors in women and men, respectively (5). Despite the tremendous efforts in the field of tumor cells biology, the drug treatment of cancers has not changed significantly and in most cases the current chemotherapy do not discriminate between normal and tumor cells (6). Moreover, the occurring drug resistance has been identified as a major problem in patients with cancer, thus numerous techniques are being utilized to overcome the former challenge (7).

Recent advances in the development of $\mathrm{N}$ containing heterocycles with anticancer activity have been made by numerous research groups (811). The introduction of heterocyclic fragments in such molecules has been found to be useful practice for modifying physicochemical properties and obtaining the optimal ADMET results for drug candidates (12). However, the demand for novel and selective anticancer agents is emerging as a major challenge for the medicinal chemists, considering the non-selective cytotoxic profiles of the current treatment (13). Specifically, an increased interest has been observed in the design of novel anticancer molecules comprising pyrrole moieties (14). The broad pharmacological profile of the latter heterocycle, together with the accessible synthetic schemes and low-cost starting materials have provided further investigations in that area (15).

In the current work, we provided a short insight into the chemistry of pyrrole, followed by its pharmacological profile, focusing mainly on the anticancer properties of the latter. Subsequently, the synthetic schemes, biological evaluations and SAR studies of recently reported anticancer pyrrole derivatives were discussed. After each reported case a modest table, comprising the essential 
moieties required for the anticancer effects was constructed.

\section{PYRROLE - PHARMACOLOGY PROFILE and ANTICANCER PROPERTIES}

Among the N-containing heterocyclic scaffolds, pyrrole has gained considerable interest due to its broad spectrum of pharmacology effects, its growing abundance in natural products, pharmaceuticals, and new materials. Pyrrole is defined as a five membered heterocyclic compound with a molecular formula of $\mathrm{C}_{4} \mathrm{H}_{5} \mathrm{~N}$. It is a volatile liquid which obtains dark color when exposed to air. Initially, pyrrole was identified as a coal tar component in 1834, however it was isolated 23 years later from the pyrolysate of a bone (16). Pyrrole is characterized as an aromatic five membered $\mathrm{N}$-containing heterocycle, differing in several key physicochemical parameters when compared to its saturated analog - pyrrolidine (Table 1) (17).

The presence of a nitrogen atom drastically increases the polarity of the structures generating a dipole moment and a marked power surface area (PSA) value, which is lacking in cyclopentane. The PSA and the lipophilicity values of pyrrole and pyrrolidine are similar, as shown above. However, the planar structure, the shorter bond lengths, as well as the higher binding free energy, represent the major dissimilarities between both $\mathrm{N}$ containing molecules. Therefore, the saturated heterocyclic system - pyrrolidine, enables a greater chance of generating structural diversity (18). The aforementioned statement has been confirmed in a paper published by Vitaku et al. (12). Moreover, the work has reported that the pyrrolidine ring is the $5^{\text {th }}$ most common five-membered $\mathrm{N}$ heterocycle accounting for 37 approved drugs. Interestingly, there are an insufficient number of pyrrole-containing FDA drugs, which places the former ring out of the top 10 scaffolds included in approved medicines. However, the pyrrole ring has a significant importance for the living organism (19). The azo-containing heterocycle is an essential part in the chlorophyll, vitamin B12, myoglobin and bile pigments (20). Moreover, the pyrrole derivatives possess a vast pharmacological profile which is of interest in various recent studies (Figure 1) (21).

Effects, such as anti-inflammatory (22), inhibition of HMG-CoA reductase (23), anticancer activity (24), inhibition of 5-hydroxytryptamine transporters (25), antihypertensive effects (26), DPP inhibition (27), modulation of AMPA (28), dopaminergic antagonism (29), progesterone receptor antagonism (30), antimalarial activity (31) and cannabinoid receptor agonism have been identified. Furthermore, numerous commercially available drugs are derivatives of pyrrole. Some examples are Atorvastatin, drug applied in the treatment of hypercholesterolemia (32), Tolmetin, used in patients with osteoarthritis and rheumatoid arthritis (33), the antibacterial macrolide Nargenicin (34) and the anticancer compound with three pyrrole scaffolds - Prodigiosin (35). Recently, a lot of attention has been drawn to the pyrrole containing antiviral agent Remdesivir, due to its potential effects against COVID-19 (Figure 2) (36).

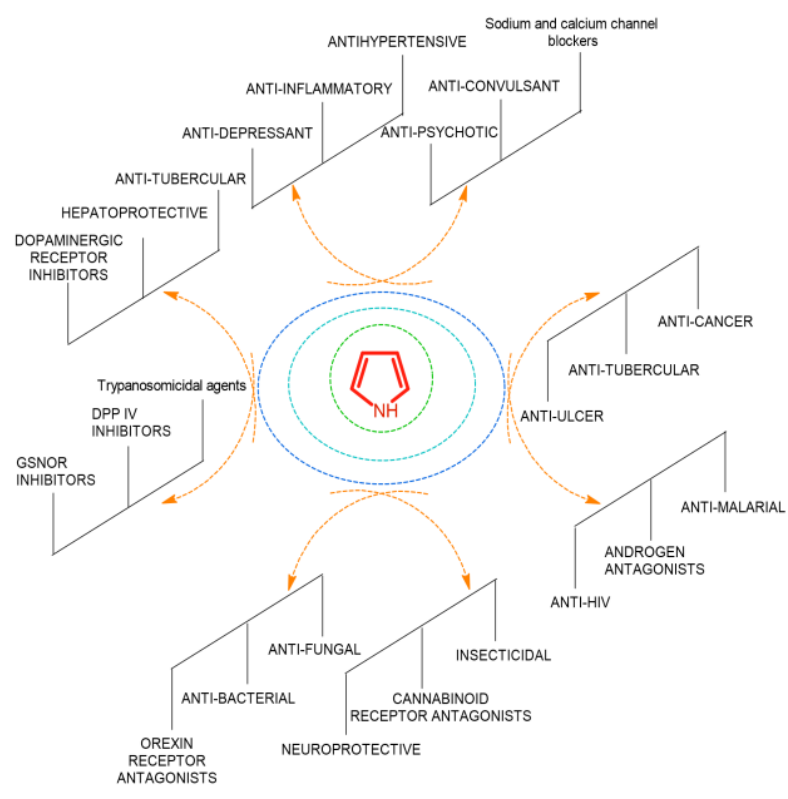

Figure 1. The pharmacological profile of pyrrole derivatives.

The cytotoxic pyrrole agents exert their anticancer effects by aiming at one or several of the following targets: $\mathrm{Bcl}-2$ family proteins, microtubules, EGFR, VEGFR-2 and AURKA kinases or inhibition of CYP1, Nuclear Factor Y and Hypoxia-inducible factors (37). The utilization of human cancer cell lines is essential for the rapid determination of cytotoxic activities of novel compounds, although the accuracy of preclinical assessment of the anticancer lead candidates remains questionable by some authors (38-40). The selective cytotoxicity of pyrrole containing compounds against cancer cell lines such as SOX2, K562, MDA-MB-231, HepG2, Hepa1-6, HT-29, and NIH3T3 have been recently reported (41-43).

Lamellarins alkaloids are suitable examples of anticancer agents including pyrrole motifs. They were initially isolated in 1985 from oceanic snails 
Table 1. 3D structures and molecular descriptors of pyrrole and pyrrolidine.

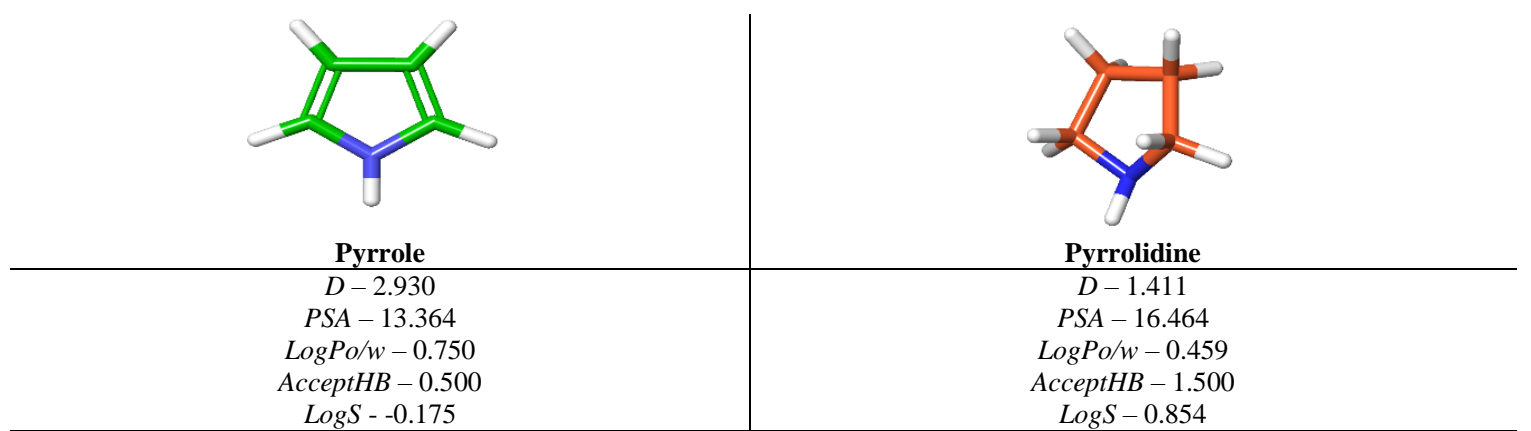

$D$ - dipole moment of the molecule; $P S A$ - power surface area; $L o g P o / w$ - octanol/water partition coefficient; AcceptHB - estimated number of hydrogen bonds accepted by the solute from water molecules in aqueous solutions; $\log S$ - predicted aqueous solubility (in mold $\mathrm{m}-3$ ).

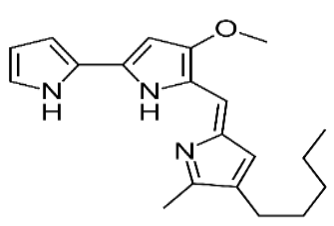

Prodigiosin (anticancer drug)<smiles>COc1ccc2c(c1)c(CC(=O)O)c(C)n2C(=O)c1ccc(Cl)cc1</smiles>

Indomethacin (NSAID)

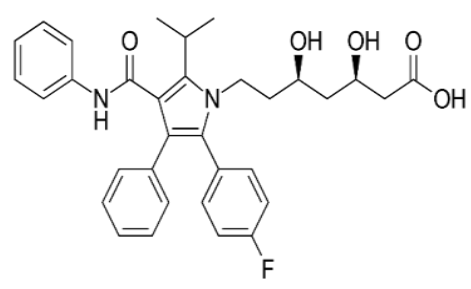

Atorvastatin (lipid-lowering drug)

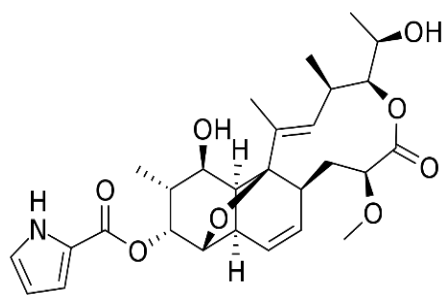

Nargenicin (antibacterial drug)

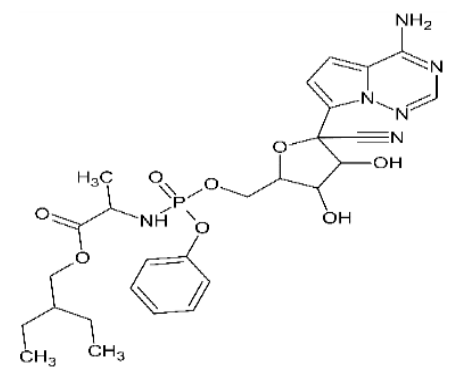

Remdesivir (antiviral)

Figure 2. Commercial drugs containing pyrrole moieties.

and soon after lamellarins were categorized as potent antagonizing agents towards topoisomerase I (44). Another natural product which comprises pyrrole as a main scaffold is tambjamine $\mathrm{D}$. The former has been found in the sea slug Tambja eliora and several reports have discussed its prominent effect towards the DNA intercalation (45).

Another greatly studied group of pyrrolebased compounds are the tetrapyrroles (46). The latter have been widely employed in cancer treatment as photosensitizers. Recent studies reported by Konícková et al. have evaluated the possible anticancer effects of Spirulina platensis and Spirulina platensis-derived tetrapyrroles against pancreatic cancer cell lines (47). Furthermore, the phyllobilins are a group of chlorophyll-derived bilin-type linear tetrapyrroles with a significant potential in the anticancer treatment (48).

Corroles (present in vitamin B12) and porphyrins are significant oligopyrrolic macrocycles utilized in the treatment of cancer. Corroles are stable molecules which function as both therapeutic and imaging anticancer agents (49). Recently, Xie et al. have reported a prominent anticancer capacity of novel tin(IV) corroles towards A549 tumor cell lines (50).

In contrast to the corroles, there has been a greater research interest for the anticancer effects of porphyrins and their derivatives $(51,52)$. A recent paper has described a considerable suppression of cell viability and tumor growth, when cationic $\mathrm{Mn}$ porphyrin $(\mathrm{MnP})$-based redox active compounds were administered (53). The study has discussed that the accumulation of 
cationic MnPs, together with their significant potency as catalysts for the oxidation of ascorbate, protein cysteines and glutathione controls the magnitude of their anticancer therapeutic effects. Mn porphyrins have been tested in vitro and in vivo for their effects against hematologic malignancies, breast cancer, head and neck cancer, glioma, prostate cancer and others. Furthermore, two Mn porphyrin analogues are already in clinical trials (Phase I and II) as radioprotectors in cancer treatment (54).

Additionally, syntheses of various promising cytotoxic agents containing pyrrole scaffolds have been recently reported (55-57). The aforementioned data demonstrates the eminent activity of the pyrrole moiety in the search for novel and selective anticancer agents. Therefore, novel pyrrole-containing anticancer agents were grouped by their main mechanism of action (or activity against specific cancer cell lines) and further discussed.

\section{MICROTUBULE POLYMERIZATION- TARGETING AGENTS}

Microtubules play a crucial role in the formation of the mitotic spindle and the movement of the chromosomes. The latter dynamic structures have turned into a successful target of anticancer drugs. Therefore, the development of novel antimicrotubule agents that possess diverse chemical profiles has led to promising activity against the proliferation of various cancer cell lines, as well as in multidrug-resistant cancers (58).

The antitumor capacity of Combretastatin A4 is well known (59). Several papers describing the synthesis of hybrid molecules between combretastatin A-4 and 1H-pyrrole-2-carboxylates have also been reported (60). In 2016, pyrrole analogues of combretastatin A-4 have been discussed by Jung et al. (61). The initial diketones have been obtained through acyl-Claisen approach and after Paal-Knorr condensation the desired pyrroles have been acquired (Figure 3).

The in vitro anticancer activity has been assessed against two human cell lines - K-562 and MDA-MB-231. The collected data showed that the diaryl substitution at $2 \mathrm{C}$ and $3 \mathrm{C}$ in the pyrrole ring has elevated the activity against the latter cancer lines. Furthermore, when aryl substitution has been presented in the pyrrole ring, the anticancer activity has decreased compared to benzyl substituent (Figure 4). Two compounds have demonstrated moderate anti-proliferative activities, however they exhibited approximately half the anticancer effect of combretastatin A-4. The most active compounds have represented $\mathrm{IC}_{50}$ values of 0.21 $\mu \mathrm{M}$ and $0.07 \mu \mathrm{M}$ against $\mathrm{K}-562$ and MDA-MB-231 cell lines, respectively.

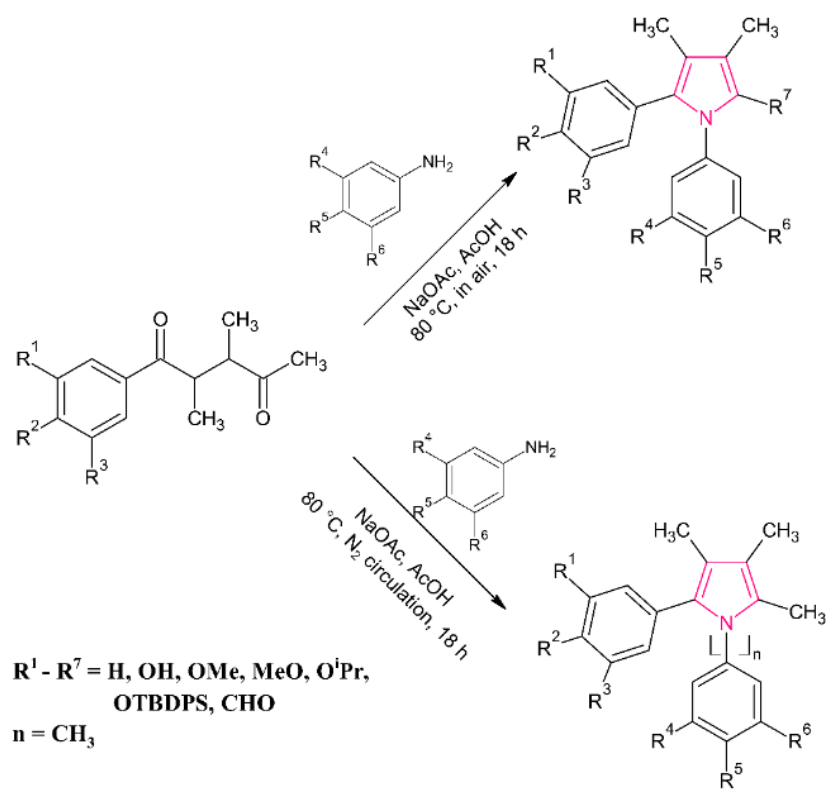

Figure 3. Synthesis of 1,2-diaryl-pyrrolic analogues of combretastatin A-4.

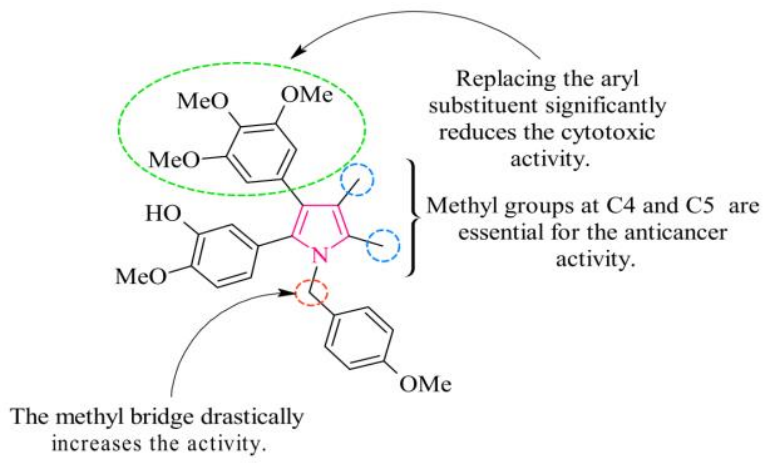

Figure 4. Key functional moieties accountable for the cytotoxic effects of pyrrole analogues of combretastatin A-4.

Novel derivatives of pyrrole-3-carboxylates have been assessed for their anticancer activity by Boichuk et al. (62). The authors have evaluated the anti-tumor properties of the described compounds against leiomyosarcoma (SK-LMS-1), gastrointestinal stromal tumor (GIST-T1), Ewing's sarcoma (A-673), RD (rhabdomyosarcoma) and (osteosarcoma) U-2 cancer cell lines and examined two novel molecules with moderate activities (Figure 5). It has been noted that the antiproliferative properties of the most prominent compounds were dose dependent. As well as inducement of G2/M cell-cycle arrest, it was observed that the aforementioned compounds have induced tumor cell death by apoptosis. 


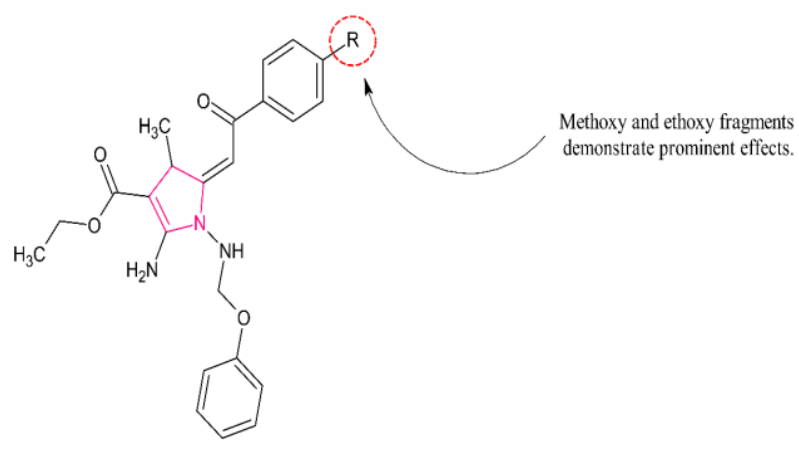

Figure 5. Fragments responsible for the anticancer effects of novel ethyl-2-aminopyrrole-3-carboxylates (EAPCs).

Spanò et al. have tested 25 novel pyrrolo[2',3':3,4]cyclohepta[1,2-d][1,2] oxazolebased compounds for their anti-tumor activities against nine human cancer cell lines (leukemia, non-small cell lung, colon, central nervous system, melanoma, ovarian, renal, prostate, and breast cancer cell lines) (63). The synthetic scheme of the aforementioned molecules is given in Figure 6.

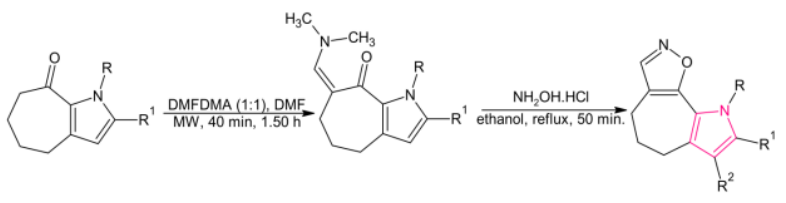

$\mathbf{R}, \mathbf{R}^{1}, \mathbf{R}^{2}=$ H, Me, 2-OMeBn, 3-OMeBn, 2,5-(OMe) $)_{2} \mathrm{Bn}$,

$\mathrm{CO}_{2} \mathrm{Et}$

Figure 6. Synthesis of novel pyrrolo[2',3':3,4]cyclohepta[1,2-d][1,2] oxazoles.

The most prominent structures have demonstrated antiproliferative activities against all cancer cell lines within $\mathrm{nM} \mathrm{GI}_{50}$ range. The authors have noted that the presence of an ethoxycarbonyl group at $8^{\text {th }}$ position was crucial for activity (Figure 7). Moreover, 3,5-dimethoxybenzyl fragments at the pyrrole nitrogen have shown the most prominent anticancer effects against melanoma, prostate and renal cancer lines. After tubulin assays, it has been discussed that the most active compounds inhibited tubulin polymerization, with IC $_{50}$ values of $1.9-8.2 \mu \mathrm{M}$. The docking studies have been performed in three crystallographic structures of tubulin (PDB codes: 1Z2B, 3N2G and 4O2B) utilizing the docking software Glide (Schrodinger). The virtual simulations have demonstrated that the improved tubulin interactions were granted from the lipophilic energy components. Moreover, molecular dynamics simulations of the most potential compounds in complex with the $4 \mathrm{O} 2 \mathrm{~B}$ model have been carried out.

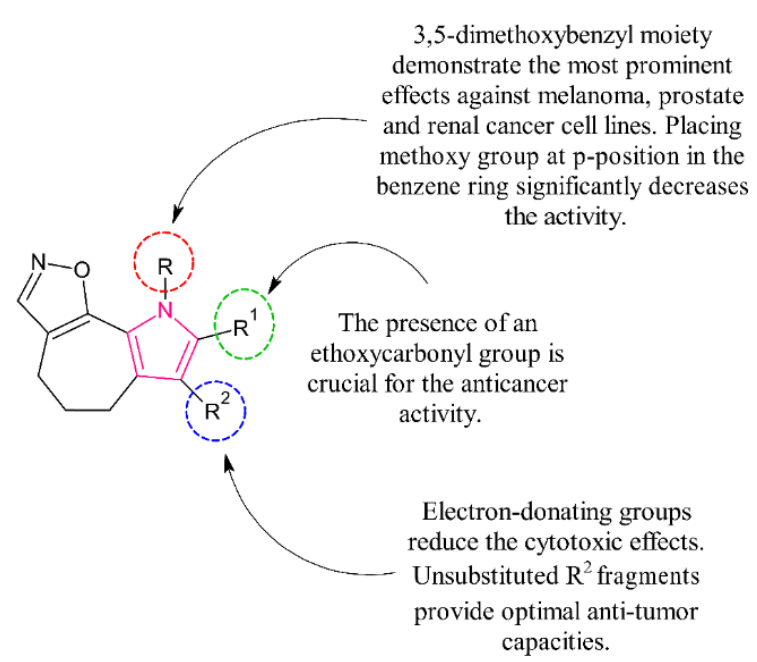

Figure 7. Key functional moieties responsible for the anticancer effects of novel pyrrolo[2',3':3,4]cyclohepta[1,2-d][1,2] oxazole derivatives.

\section{MODULATORS OF BCL-2 FAMILY MEMBERS}

A recent work published by Kilic-Kurt et al. has discussed the synthesis and anticancer properties of novel pyrrolopyrimidine derivatives (64). The synthetic scheme is given in Figure 8.

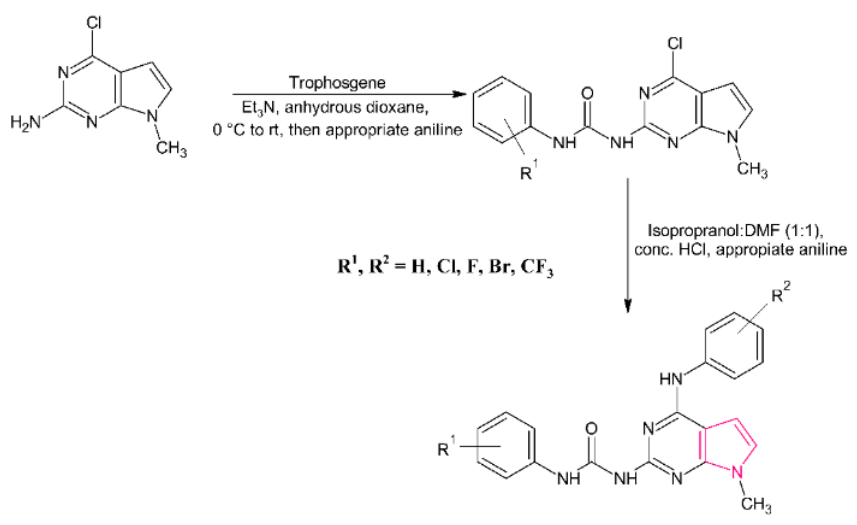

Figure 8. The synthetic scheme of novel pyrrolo[2,3d]pyrimidine derivatives.

Three cancer cell lines have been utilized for the initial evaluation - A549, PC3 and MCF-7. Most of the synthesized compounds have demonstrated higher anticancer properties against A549 and PC3 cells when compared to Imatinib. The most promising pyrrolopyrimidines demonstrated $\mathrm{IC}_{50}$ values of $0.35,1.48$ and 1.56 $\mu \mathrm{M}$, respectively, against A549 cancer cell lines. In addition, it has been found that the pyrrole compounds had induced activation of the proapoptotic proteins in the Bcl-2 family. Overall, the demonstrated anticancer capacities have shown that $\mathrm{IC}_{50}$ values against A549 cell lines were under $6 \mu \mathrm{M}$, which encouraged further research in that 
area. The structure-activity relationship is provided in Figure 9.

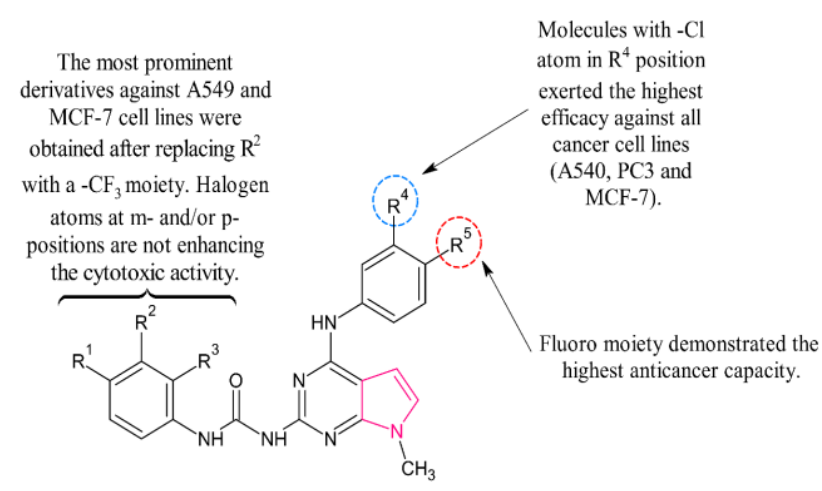

Figure 9. Essential moieties required for the anticancer effect of novel pyrrolopyrimidine derivatives.

Zhu et al. have discussed the synthesis and anticancer screening of novel substituted thiosemicarbazones with included pyrrole ring (65). The authors have discussed moderate synthetic yields after direct condensation of formyl-1H-pyrrole and 4-substituted thiosemicarbazide (Figure 10).

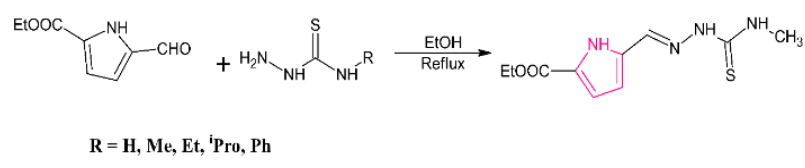

Figure 10. Reaction scheme for the synthesis of anticancer thiosemicarbazones with a pyrrole fragment.

Lung cancer PC-9, esophageal cancer Eca109 and gastric cancer SGC-7901 cell lines were employed for the determination of the cytotoxic activity. Methyl, ethyl, $i$-propyl and phenyl moieties were applied as substitutions at fourth position in the thiosemicarbazone structure (Figure 11). It has been noted that unsubstituted core structures have produced the most prominent results in all three cancer cell lines - PC-9, Eca109 and SGC-7901, with $\mathrm{IC}_{50}$ values of 44.87157 .75 33.52 , respectively. The work concluded that thiosemicarbazones with pyrrole rings could be applied for the development of novel anticancer agents.

Great variety of $\mathrm{N}$-substituted pyrroles have been synthetically implemented at place 14 in the matrine skeleton by Li et al. (Figure 12) (66).

The obtained compounds have been biologically assessed for their anticancer activity against three human cancer cell lines-SMMC7221, CNE2 and A549. Two compounds with the most significant anticancer activities against the latter cancer cell lines showed $\mathrm{IC}_{50}$ values in the range of 3.42-8.05 $\mu \mathrm{M}$, which demonstrated better activity compared to matrine. A structure-activity relationship has shown that the methoxybenzyl moiety at $\mathrm{N}$-position in the pyrrole ring considerably elevated the antitumor effect of the compounds (Figure 13). Moreover, the integration of additional methoxy groups at third position have yielded double substituted phenyl rings with the most prominent antineoplastic activity. An apoptosis of the human cancer cell lines as a result of the activity of the described compounds has been further investigated.

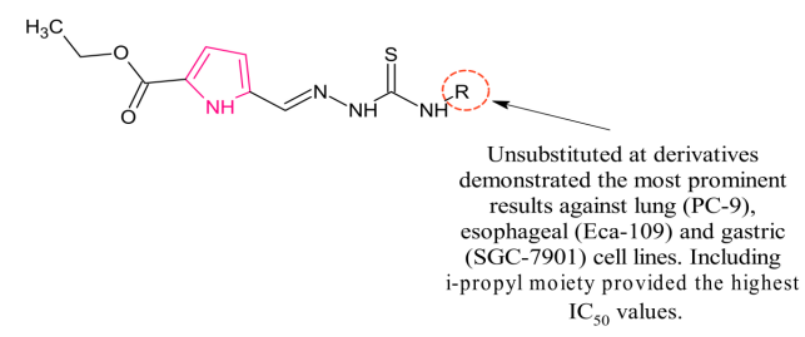

Figure 11. Key fragments responsible for the cytotoxic effects of novel N(4)-substituted thiosemicarbazones.

Fatahala et al. have reported the synthesis and the antiproliferative effects of novel substituted pyrroles (67). The synthetic scheme is given in Figure 14.

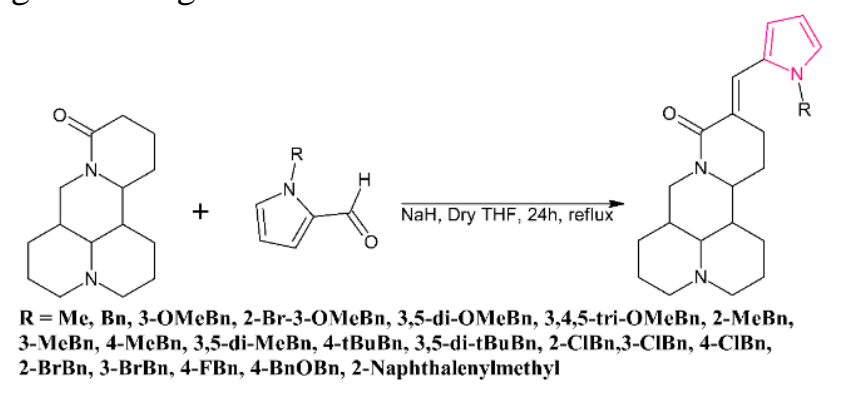

Figure 12. Synthetic route for matrine derivatives.

Their anticancer effects have been established against HepG-2 and Panc-1 cell lines. The most effective compound against both lines comprised p-methoxybenzyl and phenyl as substituents and established $\mathrm{IC}_{50}$ values in the range of 31-13 $\mu \mathrm{M}$. A phenyl moiety situated at fifth position and a 3,4-dichlorophenyl group on the nitrogen atom, resulted in moderate antineoplastic effect against HepG-2 and Panc-1 (Figure 15). Furthermore, good DPPH scavenging activity of the aforementioned compounds has been detected. 


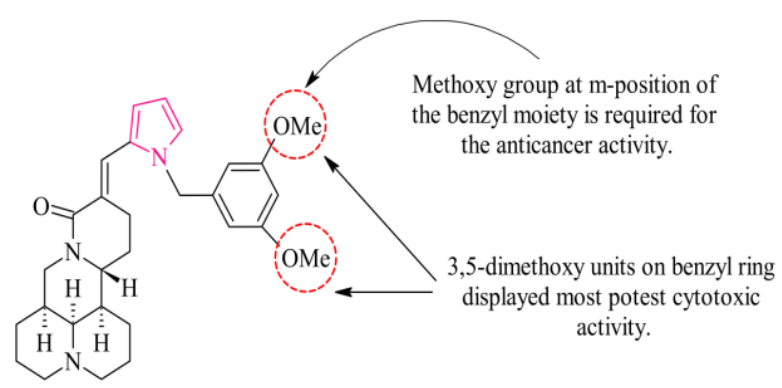

Figure 13. Key functional moieties responsible for the cytotoxic effects of new matrine derivatives with pyrrole moiety at 14 position.

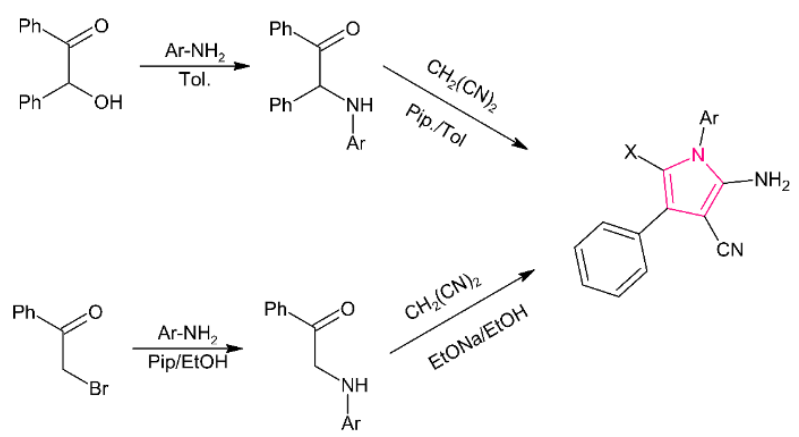

$\mathbf{X}=\mathbf{H}$ or $\mathbf{P h}$

$\mathrm{Ar}=4-\mathrm{CH}_{3}-\mathrm{C}_{6} \mathrm{H}_{4}, 4-\mathrm{OCH}_{3}-\mathrm{C}_{6} \mathrm{H}_{4}$, Antipyrine

Figure 14. Reaction scheme for the synthesis of substituted pyrroles with cytotoxic properties.

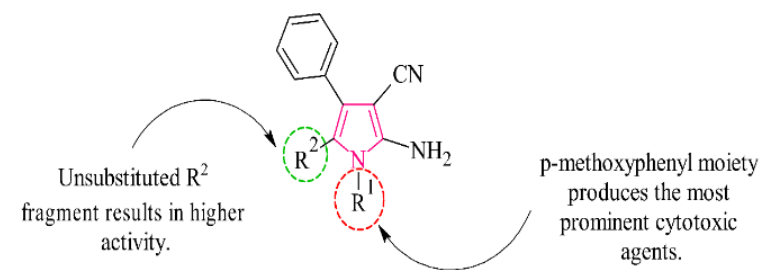

Figure 15. Key functional moieties responsible for the cytotoxic effects of novel substituted pyrroles with antiproliferative properties.

\section{TYROSINE KINASE INHIBITORS}

Bavadi et al. have reported the synthesis, in vitro and virtual evaluation of novel pyrrole derivatives with sulfonamide groups incorporating anticancer activity (68). The synthetic route to obtain pyrrole compounds bearing sulfonamide groups is given in Figure 16.

Three cancer lines were utilized for the detection of cytotoxic activity- MCF7, MOLT-4 and HL-60. The most prominent compounds have been examined to possess morpholine ring and fully substituted pyrrole ring (Figure 17). Furthermore, the authors have noted that the replacement of the morpholine moiety with phenyl or chloro groups has led to decreased cytotoxic activity. However, the demethylation of the barbituric acid at 3C had not affected the effect towards the cancer cell lines. Docking studies utilizing Autodock Vina, have shown seven hydrogen bonds between the active site of FGFR1 (PDB: 4ZSA) and the pyrrole derivatives.

Design, synthesis, and antitumor activity of novel pyrimidine-pyrroles have been discussed by Thiriveedhia et al. (69). The synthetic path of the aforementioned compounds is provided in Figure 18.

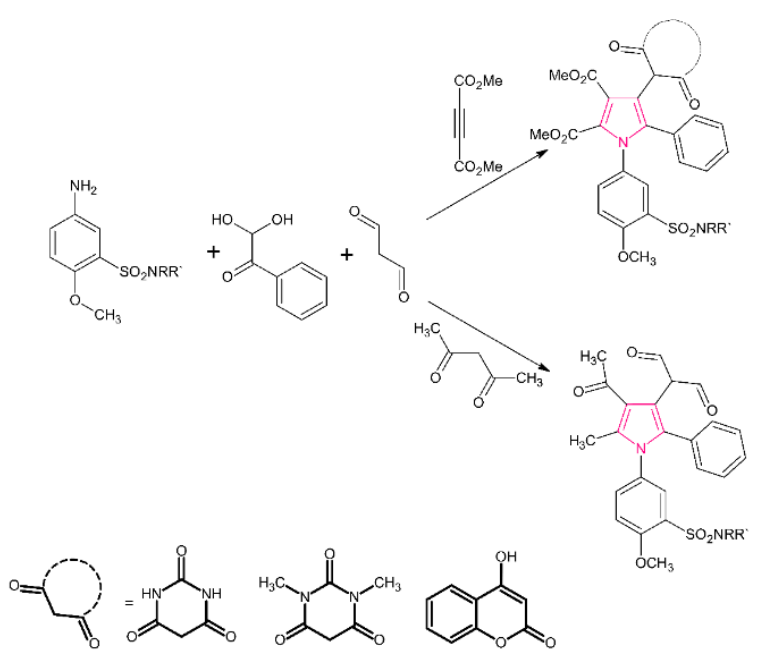

Figure 16. Synthesis of novel pyrrole derivatives bearing sulfonamide groups.

The compounds were tested against the breast cancer cell MCF-7 and the melanoma cell line B16F10. Two molecules have demonstrated $\mathrm{IC}_{50}$ values in the micromolar range (13.25-18.37 $\mu \mathrm{M})$. A biological in vitro evaluation together with molecular docking studies has enabled a construction of the structure-relationship of the synthesized compounds. It has been postulated that polar substitutes increase the cytotoxic effect of the compounds. The research group has also discussed the anticancer effect of some electron withdrawing groups. It has been noted that substituents with such properties have enhanced the overall activity of the triazoles (Figure 19). In the final stage of the work, Glide has been utilized for the docking simulations of the most prominent compounds in the active site of EGFR tyrosine kinase (PDB: 2J5F). It has been demonstrated that Cys797 played an important role in the stabilization of the complex.

P450 (CYP) are heme-containing enzymes, which participate in phase I metabolism as they hydroxylate pharmaceuticals and exogenous substances (70). 


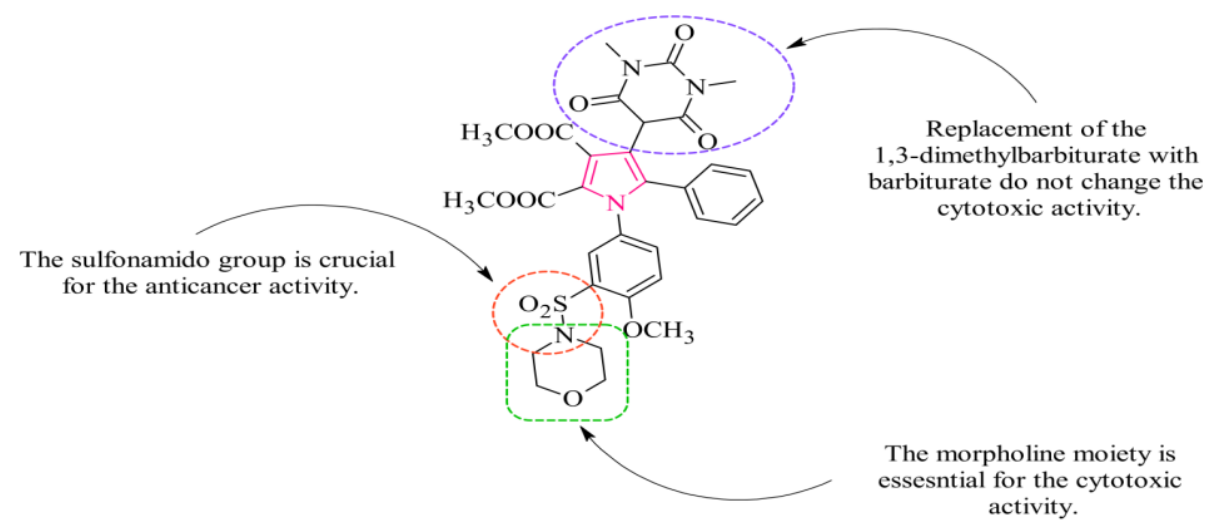

Figure 17. Essential moieties required for the anticancer effect of novel pyrrole derivatives with sulfonamide groups.

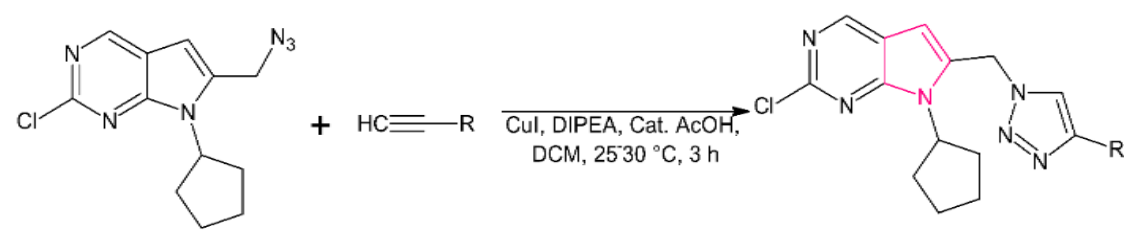

$\mathrm{R}=\mathrm{MeOH}, \mathrm{Bu}$, Pen, Hex, p-MePh,

3,4-dichlorophenyl, 3-aminophenyl

Figure 18. Synthesis of pyrimidine-pyrrole appended substituted triazole derivatives with anticancer effects.

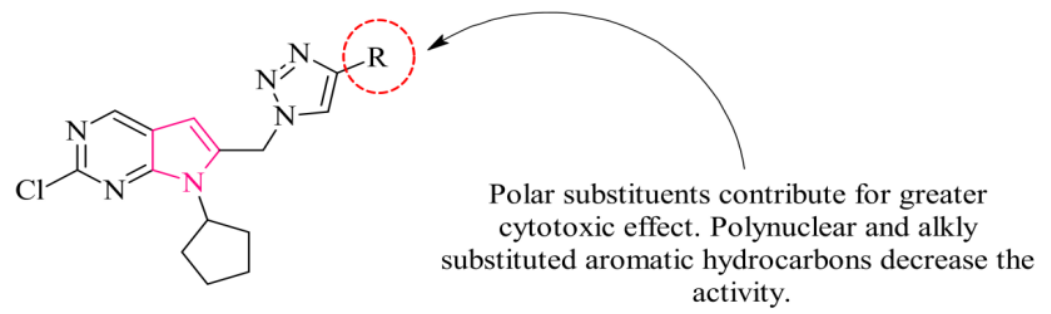

Figure 19. Key functional moieties responsible for the cytotoxic effects of novel pyrimidine-pyrrole derivatives.

Overexpression of CYP1A1 isoform may lead to DNA damage due to the formation of quinone intermediates, while the overexpression of CYP1B1 could result in enhanced metabolism of cisplatin and therefore significant reduction of its activity (71).

Recent report published by Williams et al. (72) has discussed the molecular modeling of twenty-three novel pyrrole based chalcones. The one-step synthetic scheme is given in Figure 20.

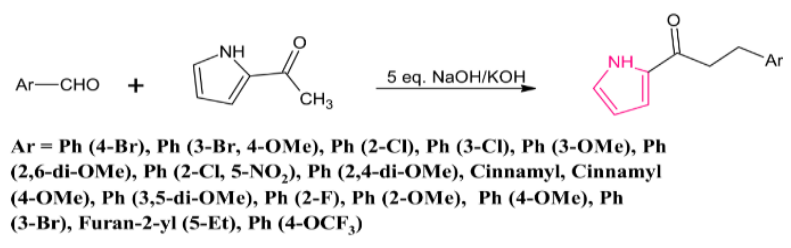

Figure 20. Synthesis of novel pyrrole-based chalcones with anticancer activities.

HEK293 cell lines have been used to identify the most prominent molecules. The authors have found that two scaffolds comprising methoxy and chloro substituents at second position possessed inhibitory effect towards all CYP1 isoenzymes, and they could be implemented for the prevention of drug-resistance in cancer therapies (Figure 21). The most prominent compounds have inhibited both CYP1A1 and CYP1B1 with an $\mathrm{IC}_{50}$ of 0.9 $\mathrm{mM}$. The authors have also emphasized on the prominence of the alkoxy group for the cytotoxic activity. Molecular docking studies were also carried out in CYP1A1 and CYP1B1 isoforms.

\section{HISTONE DEACETYLASE INHIBITORS (HDACI)}

HDACi inhibits the histone deacetylase which contributes to normal cell growth and function. The inhibitors of the latter enzyme enhance histone acetylation which leads to modification in gene expression, angiogenesis, apoptosis and metastasis. Therefore, HDACi have turned into a suitable therapeutic class to control the tumor cell growth and promote normal cellular functions (73). 


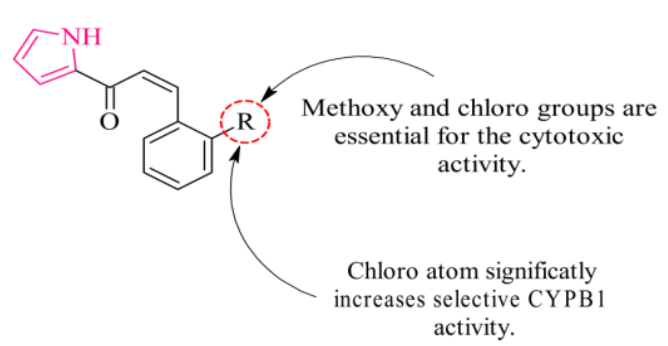

Figure 21. Key functional moieties responsible for the cytotoxic effects of pyrrole based chalcones.

Singh et al. have incorporated the pyrrole group as a connecting unit in hydroxamic acidbased histone deacetylase inhibitors (Figure 22) (74).

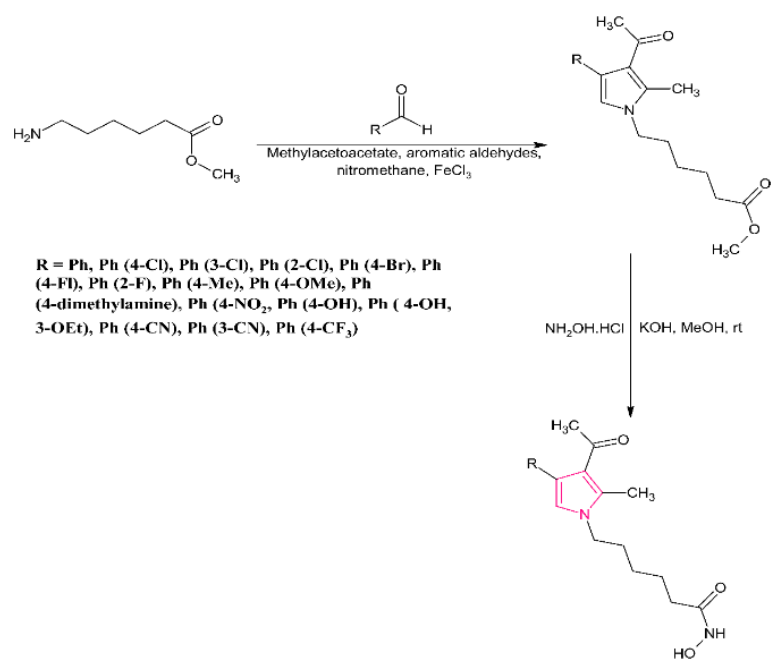

Figure 22. Synthesis of novel anticancer pyrrole derivatives.

The latter compounds have been tested in vitro for leukemia, lung, breast, and cervical human cancer cell lines. The authors have noted that p-nitro substituted molecules have induced higher antitumor activity. Moreover, active compounds have been obtained after electron donation groups such as dimethylamino, methyl, methoxy and hydroxyl, have been incorporated in the phenyl ring (Figure 23). Docking studies in the active sites of several histone deacetylase proteins (PDB:4BKX, 4LXZ, 4A69, 2VQM, 5EEI, 3COZ, 1T69, 5TD7, 1ZZ1) have indicated similar binding conformations of the aforementioned compounds as Vorinostat. The mechanism of action of the following pyrrole derivatives have not been identified, therefore we group them by the main cancer cell lines they were active against.

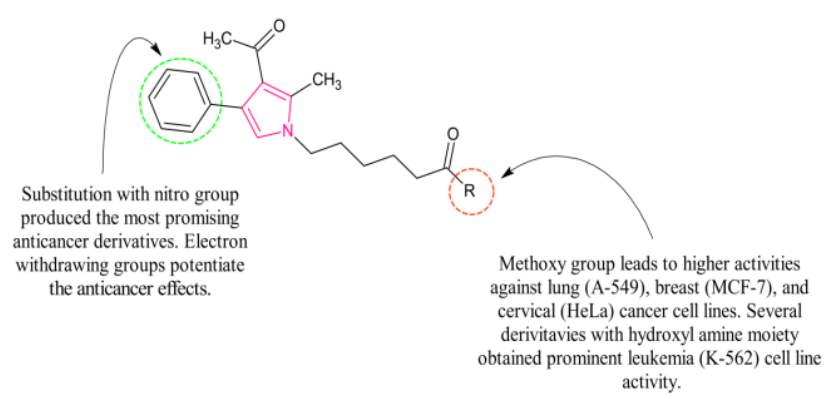

Figure 23. Key functional moieties responsible for the cytotoxic effects of pyrrole-containing hydroxamic acid-based histone deacetylase inhibitors.

\section{A549 (LUNG CANCER LINE)}

Remarkable cytotoxicity against A549 cancer cells of novel calix[4]pyrrole derivatives has been discussed by Gerreto et al. (75). The study has described meso-(p-acetamidophenyl)calix[4]pyrrole as the most active compound in the series and its pharmacokinetic properties have been further evaluated in mice. The experiment has proved moderate lipophilicity of the compound, which is associated with facile crossing through Blood-Brain-Barrier (BBB). Comparison between a meso-(p-acetamidophenyl)-calix[4]pyrrole and several similar compounds has revealed the importance of both the calix[4]pyrrole moiety and the meso acetanilide substituent for the occurring selective cytotoxicity (Figure 24).

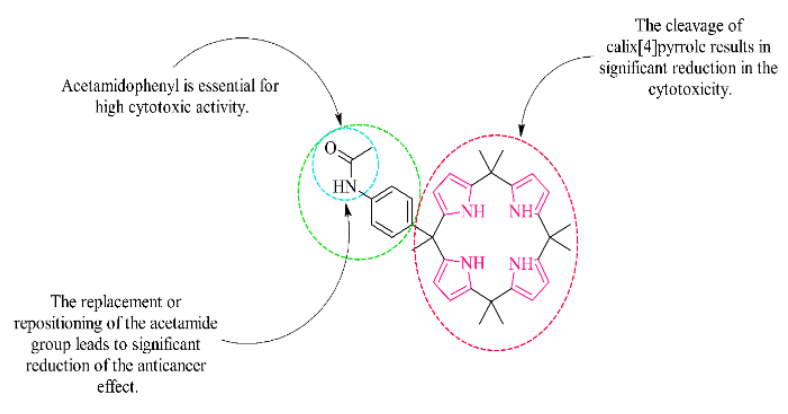

Figure 24. Key functional fragments responsible for the anticancer effects of calix[4]pyrrole derivatives.

\section{HEPG2 (LIVER CARCINOMA)}

Santoso et al. have reported four novel isatinpyrrole derivatives with moderate activity against the liver cell line - HepG2 (76). The synthesis of the former compounds is given in Figure 25.The authors have noted that the most active compound have demonstrated $\mathrm{IC}_{50}$ of $0.47 \mu \mathrm{M}$ against the human liver cancer HepG2 cell lines. 

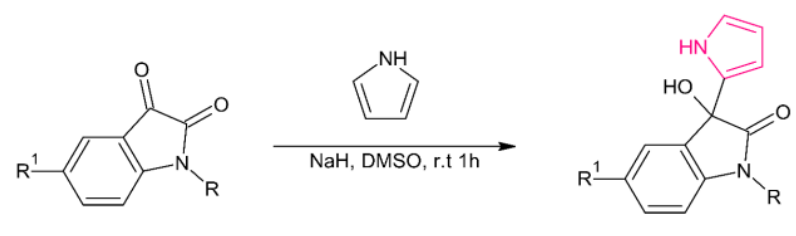

$\mathbf{R}-\mathbf{R}^{1}=\mathbf{H}, \mathrm{Me}, \mathrm{NO}_{2}, \mathrm{NH}_{2}$

Figure 25. Synthesis of novel isatin-pyrroles with cytotoxic effects.

Nine new pyrrole-alkaloid derivatives have been isolated and assessed for their cytotoxic activities by Liu et al. (77). The alkaloids have been isolated from Lepidium meyenii and structurally elucidated by 1D, 2D NMR and HRESIMS. Subsequently, the cytotoxic effects of the aforementioned compounds against HL-60, A549, SMMC-7721, MCF-7, and SW480 cell lines were evaluated using the MTS method. The most active pyrrole derivative displayed selective cytotoxicity against SMMC-7721 cancer cell line with $\mathrm{IC}_{50}$ value of $16.78 \mu \mathrm{M}$. The essential moieties required for the cytotoxic activities are given in Figure 26.

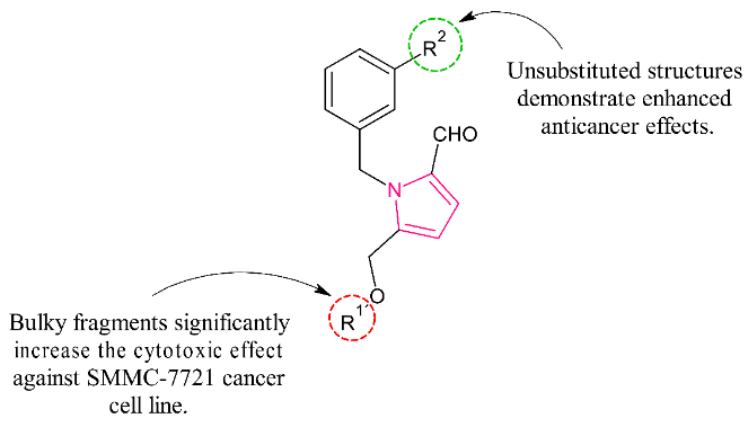

Figure 26. Key functional fragments responsible for the anticancer effects of novel pyrrole-alkaloid derivatives.

\section{HELA (CERVIX CARCINOMA)}

Khalipour \& Asghari have synthesized and evaluated the cytotoxic effect of novel dihydropyrimidone substituted pyrroles (78). The synthesis has been carried out utilizing threecomponent reaction (Figure 27).

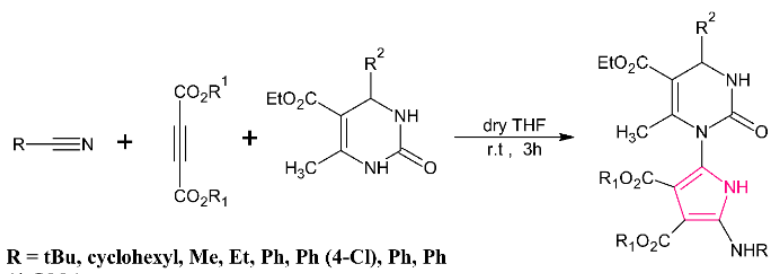
(4-OMe)

Figure 27. Synthesis of novel dihydropyrimidone substituted pyrroles.
HeLa cancer cell lines have been utilized for the determination of the cytotoxic effect. Two of the reported compounds have demonstrated good $\mathrm{IC}_{50}$ values of 10.36 and $9.90 \mu \mathrm{M}$ against the former cell line. The authors have noted that the pchlorophenyl moiety as $\mathrm{R}^{2}$ substitution is essential for the anticancer effect (Figure 28). Furthermore, the methyl esters have demonstrated higher cytotoxicity against cell lines in comparison with the ethyl esters. The former have displayed moderate anticancer activity in comparison to doxorubicin. In addition, the work has discussed good antioxidant properties of the aforementioned molecules.

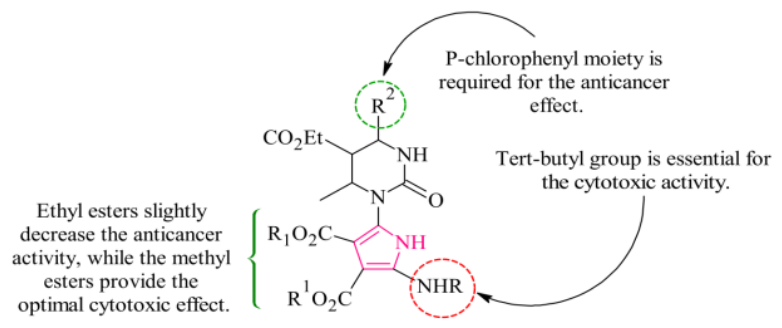

Figure 28. Key functional moieties responsible for the cytotoxic effects of novel dihydropyrimidone substituted pyrroles.

\section{CACO-2 AND HCT116 (HUMAN COLON CARCINOMA)}

The synthesis and antiproliferation activities of novel pyrrolidines and pyrroles have been examined by Ji et al. (79). The synthesis of the pyrroles is given in Figure 29.

When compared to pyrrolidines, the pyrrole derivatives did not demonstrate efficient anticancer properties. The latter have been examined for inhibition of HCT116 cell proliferation. Derivatives with m-bromo substituted phenyl groups were assessed as the most active compounds (Figure 30). The exact underlying mechanism of the aforementioned compounds was not investigated due to the poor performance of the pyrrole molecules.
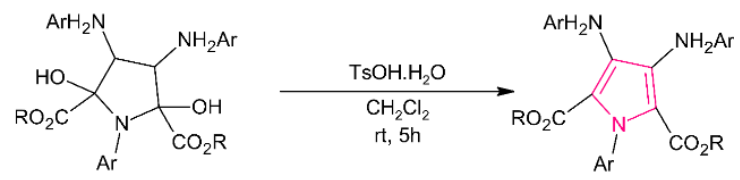

$\mathbf{R}=\mathbf{H}, \mathbf{B r}, \mathbf{F}, \mathrm{Me}, \mathbf{E t}, \mathrm{t}-\mathrm{Bu}, \mathrm{OCF}_{3}, \mathrm{CF}_{3}$,

Figure 29. Synthesis of novel substituted pyrroles. 


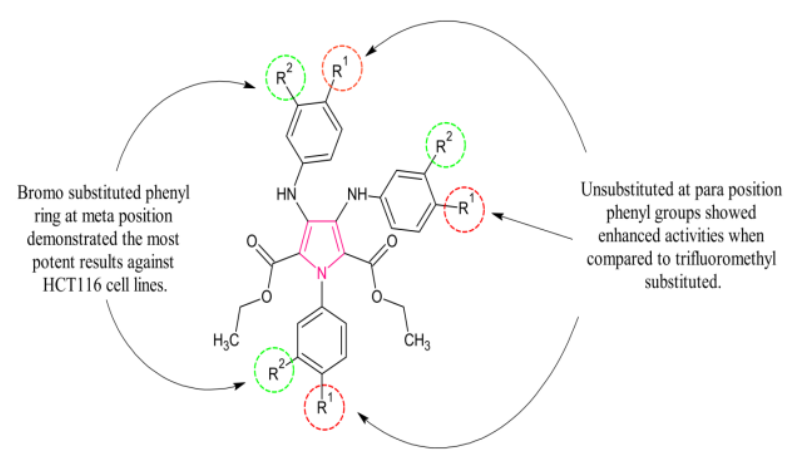

Figure 30. Key functional moieties responsible for the cytotoxic effects of novel substituted pyrroles with antiproliferative effects.

The anticancer activity of novel palladium (II) and platinum (II) complexes with pyrroles has been reported by Mbugua et al. (80). The cytotoxic effects have been examined against one noncancerous (MCF-12A) and five cancerous cell lines (Caco-2, HeLa, HepG2, MCF-7, and PC-3). A compound with dimethyl sulfoxide moiety has shown the highest selectivity against all cancerous cell lines. The authors have discussed that the former molecule have demonstrated $\mathrm{IC}_{50}$ values of $15.81,64.5,24.9,45.5,13.0,20.9 \mu \mathrm{g} / \mathrm{mL}$ against Caco-2, MCF-7, MCF-12A, HeLa, Hep-G2 and PC-3, respectively. Furthermore, it has been noted that the bulky substitutions on platinum atoms did not yield structures with higher anticancer activity as described in other works (Figure 31). That conclusion clearly does not agree with previous reports, which have discussed low anticancer activity of bulky Pd or Pt structures (81).

\section{PANC AND ASPC-1 (HUMAN PANCREATIC CANCER CELL LINES)}

Paper published in 2019 presented the microwave synthesis and anticancer screening of novel pyrrole-imidazole derivatives (82). The authors have discussed a facile and efficient method via a post-Ugi cascade reaction followed by one purification procedure (Figure 32).

Human pancreatic cancer cell lines PANC and ASPC-1 have been utilized for the biological evaluation. Further testing towards prostate cancer cells A549 and PC-3 has been carried out and it has been concluded that the most active compound was more effective towards the pancreatic cancer cells with $\mathrm{IC}_{50}$ values of 0.063 and $0.062 \mu \mathrm{M}$. From the results it has been clear that the replacement or the removal of p-chloro atoms in the phenyl moiety,

\section{MDA-MB AND MCF-7 CELL LINE (HUMAN BREAST CANCER CELL LINE)}

placed at N2, had caused significant drop of the anticancer activity. The most promising compound (Figure 33) was 10 times more selective towards the pancreas than prostate cell lines, which highlights its high selectivity.

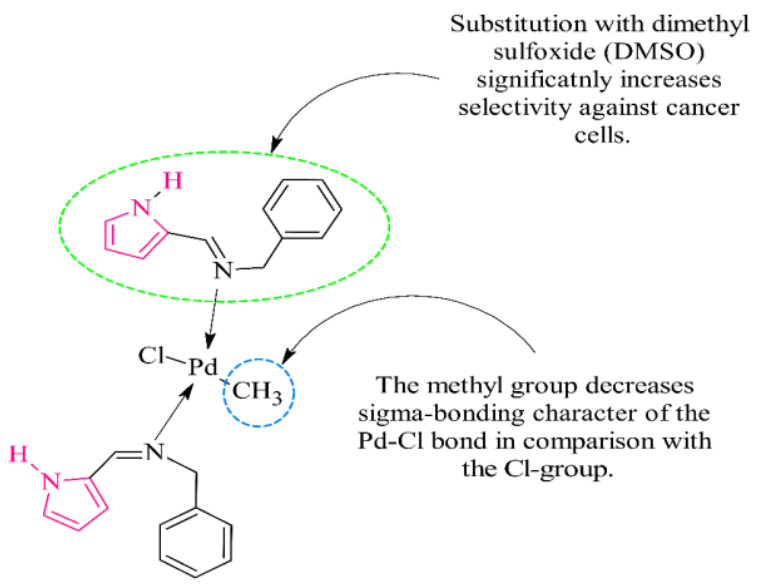

Figure 31. Key functional moieties responsible for the cytotoxic effects of palladium anticancer derivatives complexed with pyrroles.

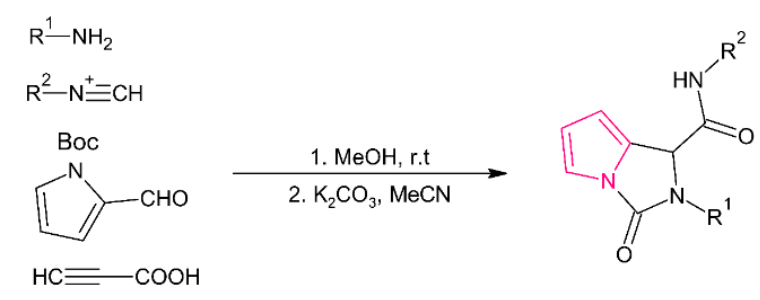

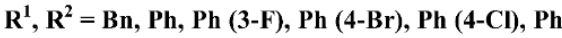
(2,4-di-Cl), Ph (4-F), Ph (3-F), Ph (3-F, 4-Cl), Piperazine

Figure 32. Synthetic route for pyrrolo-imidazole derivatives.

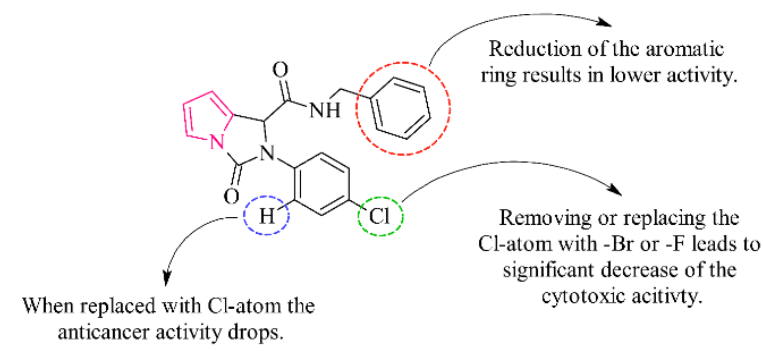

Figure 33. Key functional moieties responsible for the cytotoxic effects of pyrrole-imidazole derivatives possessing anticancer activity.

A recent work has reported the synthesis of a series of 2,4-dimethylpyrrole derivatives (83). The 
amide coupling reaction scheme is given in Figure 34.

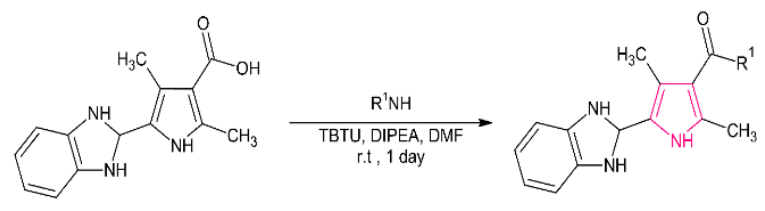

$\mathbf{R}^{1}=$ Propylamine, Isobutylamine, Piperazine, Pyrrolidine, Morpholine, Cyclohexylamine, Piperidine, Hydrazine, Imidazole, 3,5-Dimethylpyrazole, Phenylhydrazine, 4-Chlorophenylhydrazine

Figure 34. Synthetic scheme for 2,4-dimethyl-1Hpyrrole-3-carboxamide anticancer derivatives.

The anticancer activities of the latter were evaluated in NCI 60-cell line panel against leukemia, melanoma, lung, colon, CNS, ovarian, renal, prostate and breast cancer cell lines at a single $10 \mu \mathrm{M}$ concentrations. The most eminent structure comprised 1-cyclohexylethylamine as a substituent (Figure 35). The former have demonstrated notable growth inhibition against the epithelial, human breast cancer cell line - MDAMB. In silico ADME simulations have obtained promising results for further evaluation of the aforementioned compounds.

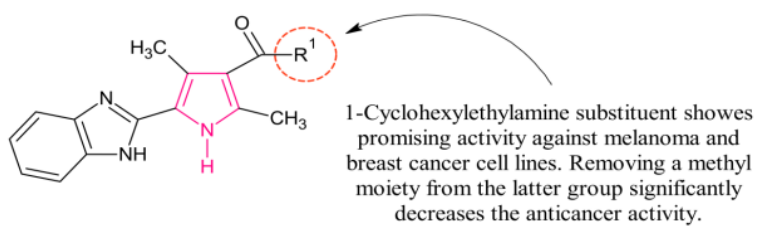

Figure 35. Key functional moieties responsible for the cytotoxic effects of 2,4-dimethylpyrrole derivatives with potential anticancer effects.

Toubia et al. have demonstrated the anticancer evaluation of three novel bimetal compounds containing a gold(III) porphyrin conjugated to a platinum diamine moiety (84). Three novel complexes differing in the type of diamine ligand around platinum(II): ammonia $\left(\mathrm{NH}_{3}\right)$, cyclohexanediamine (CyDA), and pyridylmethylamine (Py), have been discussed in the paper. The anticancer effects of the conjugates were screened against human fibroblast cells (FS68) and human breast cancer cells (MCF-7). The CyDA derivative exhibited the most prominent cytotoxic capacity among the series. The aforementioned compound has demonstrated an $\mathrm{IC}_{50}$ value of $1,81 \mu \mathrm{M}$ agsinst MCF-7 cell lines. Overall, the authors have noted that $\mathrm{Au}(\mathrm{III}) / \mathrm{Pt}$ (II) complexes were more effective by $2-5,6$ fold compared to the corresponding platinum complexes (Figure 36).

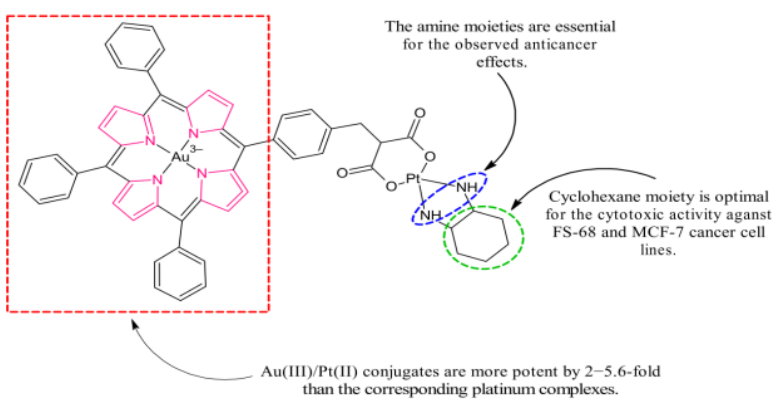

Figure 36. Key functional moieties responsible for the cytotoxic effects of gold porphyrin linked to malonate diamine platinum complexes.

\section{ACTIVE AGAINST MULTIPLE CANCER CELL LINES}

Zhan et al. have assessed the anticancer activity of novel $1 \mathrm{H}$-pyrrole derivatives (85). The synthetic route of the latter compounds is provided in Figure 37.

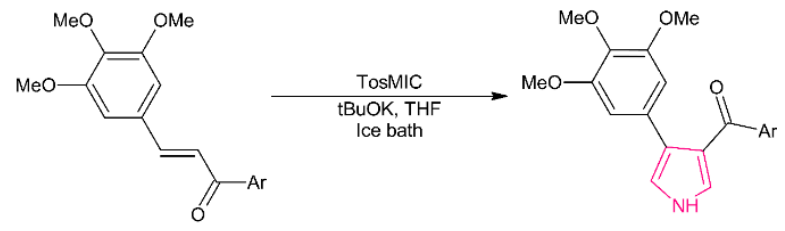

$\mathrm{Ar}=\mathrm{Ph}(2-\mathrm{F}), \mathrm{Ph}(4-\mathrm{F}), \mathrm{Ph}$ (2-Cl), Ph (4-Br), Ph (4-Me), Ph (2,4-di-Me), Ph (3-Br), Ph (4-Cl), Ph (3-OMe), Ph (4-OMe), 2-Pyridinyl, Naphthalene, Thiophene

Figure 37. Synthetic route of 3-(substituted aroyl)-4(3,4,5-trimethoxyphenyl)-1H-pyrrole derivatives.

The cytotoxic evaluation has been carried out against eleven cancer and two normal lines. The most prominent pyrrole $\left(\mathrm{IC}_{50}=8.2-31.7 \mu \mathrm{M}\right)$ was bearing 4-bromophenyl as a substituent at third position (Figure 38). Replacing the bromine atom with fluoro, chloro, methyl or methoxy moieties have drastically reduced the anticancer activity against A375, CT-26, HeLa, MGC 80-3, NCIH460 and SGC-7901 cells. A 2-pyridyl moiety has been active only against MGC80-3, while a 3pyridinyl has not demonstrated any anticancer activity. It has been also pointed out that a 3,4,5trimethoxy phenyl fragment has not shown any significant activity compared with the 4-methylthio phenyl group. However, the discussed components have manifested higher anticancer effects in contrast with 4-methoxyphenyl moiety. Overall, the aforementioned compounds have demonstrated good antiproliferative activity against several cancer cell lines and low toxic potential. 


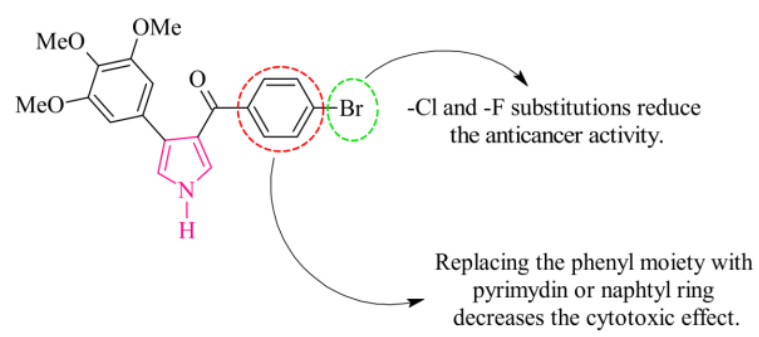

Figure 38. Key functional moieties responsible for the cytotoxic effects of novel $1 \mathrm{H}$-pyrrole derivatives.

\section{CONCLUSION AND FUTURE PERSPECTIVES}

The pyrrole moiety has been extensively examined over the past few decades for its anti-inflammatory, antioxidant, anti-depressant, anti-bacterial, antifungal and antihypertensive effects. Among the broad range of therapeutic applications, the anticancer activity of the latter scaffold has emerged recently as a prominent scaffold for future research. Pyrrole-based compounds demonstrate prominent in vitro and in vivo capacities against several types of cancer, including lung cancer, cervix carcinoma, pancreatic cancer, prostate cancer, breast cancer and colorectal cancer. This review described the anti-tumor potential of various novel pyrrole derivatives that have been published in the literature. In most of the reported cases, synthetic schemes together with figures of the key functional moieties accountable for the optimal cytotoxic effects, were provided. Essentially, various substituted pyrrole derivatives have been discussed as potent anticancer agents with easily accessible synthetic schemes and lowcost starting materials. However, further in vivo studies in most of the papers are needed. Overall, we believe that the implementation of a substituted pyrrole nucleus could be essential to establish the clinical success of novel anticancer compounds and this work could be beneficial for the design and synthesis of novel and effective pyrrole-containing anticancer agents based on the aforementioned synthetic routes and key moieties required for the biological activity.

CONFLICT OF INTEREST. The authors declare no conflict of interest.

\section{REFERENCES}

1. Hassanpour SH, Dehghani M. Review of cancer from perspective of molecular. J Cancer Res Pract, 2017; 4(4):127-9. DOI:10.1016/j.jcrpr.2017.07.001

2. Qin J-J, Yan L, Zhang J, Zhang W-D. STAT3 as a potential therapeutic target in triple negative breast cancer: a systematic review. Journal of experimental \& clinical cancer research : CR, 2019; 38(1):195-. DOI:10.1186/s13046-0191206-z

3. Byrne HM, Alarcon T, Owen MR, Webb SD, Maini PK. Modelling aspects of cancer dynamics: a review. Phil Trans R Soc A, 2006; 364:1563-78. DOI:doi.org/10.1098/rsta.2006.1786

4. Saito Y, Koya J, Araki M, Kogure Y, Shingaki S, Tabata $\mathrm{M}$, et al. Landscape and function of multiple mutations within individual oncogenes. Nature, 2020; 582(7810):95-9. DOI:10.1038/s41586-020-2175-2

5. Smith RA, Andrews KS, Brooks D, Fedewa SA, Manassaram-Baptiste D, Saslow D, et al. Cancer screening in the United States, 2018: A review of current American Cancer Society guidelines and current issues in cancer screening. CA Cancer $\mathbf{J}$ Clin, 2018; 68(4):297-316. DOI:10.3322/caac. 21446

6. Li Y, Lei Y, Yao N, Wang C, Hu N, Ye W, et al. Autophagy and multidrug resistance in cancer. Chin J Cancer, 2017; 36(52). DOI:10.1186/s40880-017-0219-2

7. Juchum M, Günther M, Laufer SA. Fighting cancer drug resistance: Opportunities and challenges for mutation-specific EGFR inhibitors. Drug Resist Updat, 2015; 20:12-28. DOI:10.1016/j.drup.2015.05.002

8. Karaaslan C, Doganc F, Alp M, Koc A, Karabay AZ, Göker H. Regioselective N-alkylation of some imidazole-containing heterocycles and their in vitro anticancer evaluation. J Mol Struct, 2020; 1205:127673.

DOI:10.1016/j.molstruc.2019.127673

9. Facchetti G, Rimoldi I. Anticancer platinum(II) complexes bearing $\mathrm{N}$-heterocycle rings. Bioorg Med Chem Lett, 2019; 29(11):1257-63. DOI:10.1016/j.bmcl.2019.03.045

10. A Patil S, P Hoagland A, A Patil S, Bugarin A. Nheterocyclic carbene-metal complexes as bioorganometallic antimicrobial and anticancer drugs, an update (2015-2020). Future Med Chem, 2020; 12(24):2239-75. DOI:10.4155/fmc-20200175

11. Ardiansah B. RECENT REPORTS ON PYRAZOLE-BASED BIOACTIVE COMPOUNDS AS CANDIDATE FOR ANTICANCER AGENTS. Asian J Pharm Clin Res, 2017; 10(12):45. DOI:10.22159/ajpcr.2017.v10i12.22065

12. Vitaku E, Smith DT, Njardarson JT. Analysis of the Structural Diversity, Substitution Patterns, and Frequency of Nitrogen Heterocycles among U.S. FDA Approved Pharmaceuticals. J Med Chem, 2014; 57(24):10257-74. DOI:10.1021/jm501100b

13. Balaji NV, Ramani MV, Viana AG, Sanglard LP, White J, Mulabagal V, et al. Design, synthesis and in vitro cell-based evaluation of the anti-cancer 
activities of hispolon analogs. Bioorg Med Chem, 2015; 23(9):2148-58. DOI:10.1016/j.bmc.2015.03.002

14. Vaijayanthi T, Bando T, Pandian GN, Sugiyama H. Progress and Prospects of Pyrrole-Imidazole Polyamide-Fluorophore Conjugates as SequenceSelective DNA Probes. Chembiochem, 2012; 13(15):2170-85.

DOI:https://doi.org/10.1002/cbic.201200451

15. Bianco MdCAD, Marinho DILF, Hoelz LVB, Bastos MM, Boechat N. Pyrroles as Privileged Scaffolds in the Search for New Potential HIV Inhibitors. Pharmaceuticals (Basel), 2021; 14(9):893. DOI:10.3390/ph14090893

16. Gholap SS. Pyrrole: An emerging scaffold for construction of valuable therapeutic agents. Eur J Med Chem, 2016; 110:13-31. DOI:10.1016/j.ejmech.2015.12.017

17. Li Petri G, Raimondi MV, Spanò V, Holl R, Barraja P, Montalbano A. Pyrrolidine in Drug Discovery: A Versatile Scaffold for Novel Biologically Active Compounds. Top Curr Chem (Cham), 2021; 379(5):34-. DOI:10.1007/s41061021-00347-5

18. Clemons PA, Wilson JA, Dančík V, Muller S, Carrinski HA, Wagner BK, et al. Quantifying structure and performance diversity for sets of small molecules comprising small-molecule screening collections. Proc Natl Acad Sci U S A, 2011;

DOI:10.1073/pnas.1015024108

19. Ahmad S, Alam O, Naim MJ, Shaquiquzzaman M, Alam MM, Iqbal M. Pyrrole: An insight into recent pharmacological advances with structure activity relationship. Eur J Med Chem, 2018; 157:527-61. DOI:10.1016/j.ejmech.2018.08.002

20. S.I. Abou-Elmagd W, Abdel Aziz A, I. Hashem A. Synthesis and Antimicrobial Activity Evaluation of the Pyrrole-Derived Heterocycles Bearing Two Functionalities. Curr Org Synth, 2016; 14(1):137-42. DOI:10.2174/1570179413666160625075307

21. Tarzia G, Duranti A, Tontini A, Spadoni G, Mor M, Rivara S, et al. Synthesis and structureactivity relationships of a series of pyrrole cannabinoid receptor agonists. Bioorg Med Chem, 2003; 11(18):3965-73. DOI:10.1016/s09680896(03)00413-9

22. do Nascimento TA, Dutra FVA, Pires BC, Borges KB. Efficient removal of anti-inflammatory phenylbutazone from an aqueous solution employing a composite material based on poly(aniline-co-pyrrole)/multi-walled carbon nanotubes. New J Chem, 2018; 42(9):7030-42. DOI:10.1039/c8nj00861b

23. Jalaja R, Leela SG, Mohan S, Nair MS, Gopalan RK, Somappa SB. Anti-hyperlipidemic potential of natural product based labdane-pyrroles via inhibition of cholesterol and triglycerides synthesis. Bioorg Chem, 2021; 108:104664. DOI:10.1016/j.bioorg.2021.104664

24. Lang DK, Kaur R, Arora R, Saini B, Arora S. Nitrogen-Containing Heterocycles as Anticancer Agents: An Overview. Anticancer Agents Med Chem, 2020; 20(18):2150-68. DOI:10.2174/1871520620666200705214917

25. Pullar IA, Carney SL, Colvin EM, Lucaites VL, Nelson DL, Wedley S. LY367265, an inhibitor of the 5-hydroxytryptamine transporter and 5hydroxytryptamine $2 \mathrm{~A}$ receptor antagonist: a comparison with the antidepressant, nefazodone. Eur J Pharmacol, 2000; 407(1-2):39-46. DOI:10.1016/s0014-2999(00)00728-7

26. Demirayak S, Karaburun AC, Beis R. Some Pyrrole Substituted Aryl Pyridazinone and Phthalazinone Derivatives and Their Antihypertensive Activities. ChemInform, 2005; 39(12):1089-95.

DOI:10.1016/j.ejmech.2004.09.005

27. Wu D, Jin F, Lu W, Zhu J, Li C, Wang W, et al. Synthesis, Structure-Activity Relationship, and Pharmacophore Modeling Studies of Pyrazole-3Carbohydrazone Derivatives as Dipeptidyl Peptidase IV Inhibitors. Chem Biol Drug Des, 2012; 79(6):897-906. DOI:10.1111/j.17470285.2012.01365.x

28. Jin R, Clark S, Weeks AM, Dudman JT, Gouaux E, Partin KM. Mechanism of positive allosteric modulators acting on AMPA receptors. The Journal of neuroscience : the official journal of the Society for Neuroscience, 2005; 25(39):9027-36. DOI:10.1523/JNEUROSCI.2567-05.2005

29. Nakajima S, Gerretsen P, Takeuchi H, Caravaggio F, Chow T, Le Foll B, et al. The potential role of dopamine $\mathrm{D}_{3}$ receptor neurotransmission in cognition. European neuropsychopharmacology : the journal of the European College of Neuropsychopharmacology, 2013; 23(8):799813. DOI:10.1016/j. euroneuro.2013.05.006

30. Zhang P, Terefenko E, Kern J, Fensome A, Trybulski E, Unwalla R, et al. 5-(3-Cyclopentyl2-thioxo-2,3-dihydro-1H-benzimidazol-5-yl)-1methyl-1H-pyrrole-2-carbonitrile: A novel, highly potent, selective, and orally active nonsteroidal progesterone receptor agonist. Bioorg Med Chem, 2007; 15(20):6556-64. DOI:10.1016/j.bmc.2007.07.011

31. Diaz CA, Allocco J, Powles MA, Yeung L, Donald RGK, Anderson JW, et al. Characterization of Plasmodium falciparum cGMP-dependent protein kinase (PfPKG): Antiparasitic activity of a PKG inhibitor. Mol Biochem Parasitol, 2006; 146(1):78-88. DOI:10.1016/j.molbiopara.2005.10.020

32. Carvalho RCC, Martins WA, Silva TP, Kaiser CR, Bastos MM, Pinheiro LCS, et al. New pentasubstituted pyrrole hybrid atorvastatinquinoline derivatives with antiplasmodial activity. 
Bioorg Med Chem Lett, 2016; 26(8):1881-4. DOI:10.1016/j.bmcl.2016.03.027

33. Ramadan AA, Elbakry AM, Esmaeil AH, Khaleel SA. Pharmaceutical and pharmacokinetic evaluation of novel rectal mucoadhesive hydrogels containing tolmetin sodium. J Pharm Investig, 2018; 48(6):673-83. DOI:10.1007/s40005-017-0365-1

34. Pidot SJ, Herisse M, Sharkey L, Atkin L, Porter JL, Seemann T, et al. Biosynthesis and EtherBridge Formation in Nargenicin Macrolides. Angew Chem Int, 2019; 131(12):4036-41. DOI:10.1002/ange.201900290

35. Wang Z, Li B, Zhou L, Yu S, Su Z, Song J, et al. Prodigiosin inhibits $W n t / \beta$-catenin signaling and exerts anticancer activity in breast cancer cells. Proc Natl Acad Sci U S A, 2016; 113(46):131505. DOI:10.1073/pnas.1616336113

36. Al-Tawfiq JA, Al-Homoud AH, Memish ZA. Remdesivir as a possible therapeutic option for the COVID-19. Travel Med Infect Dis, 2020; 34:101615-. DOI:10.1016/j.tmaid.2020.101615

37. Li Petri G, Spanò V, Spatola R, Holl R, Raimondi $\mathrm{MV}$, Barraja $\mathrm{P}$, et al. Bioactive pyrrole-based compounds with target selectivity. Eur J Med Chem, 2020; 208:112783-. DOI:10.1016/j.ejmech.2020.112783

38. Sharma SV, Haber DA, Settleman J. Cell linebased platforms to evaluate the therapeutic efficacy of candidate anticancer agents. Nature Reviews Cancer, 2010; 10(4):241-53. DOI: $10.1038 / \mathrm{nrc} 2820$

39. Lacroix M. Persistent use of "false" cell lines. Int J Cancer, 2007; 122(1):1-4. DOI:10.1002/ijc.23233

40. Borrell B. How accurate are cancer cell lines? Nature, 2010; 463(7283):858-. DOI:10.1038/463858a

41. Malinee M, Kumar A, Hidaka T, Horie M, Hasegawa K, Pandian GN, et al. Targeted suppression of metastasis regulatory transcription factor SOX2 in various cancer cell lines using a sequence-specific designer pyrrole-imidazole polyamide. Bioorg Med Chem, 2020; 28(3):115248. DOI:10.1016/j.bmc.2019.115248

42. Bandyopadhyay D, Mukherjee S, Granados JC, Short JD, Banik BK. Ultrasound-assisted bismuth nitrate-induced green synthesis of novel pyrrole derivatives and their biological evaluation as anticancer agents. Eur J Med Chem, 2012; 50:209-15. DOI:10.1016/j.ejmech.2012.01.055

43. Bando T, Iida H, Tao Z-F, Narita A, Fukuda N, Yamori T, et al. Sequence Specificity, Reactivity, and Antitumor Activity of DNA-Alkylating Pyrrole-Imidazole Diamides. Chem Biol, 2003; 10(8):751-8. DOI:10.1016/s1074$5521(03) 00160-1$
44. Bailly C. Anticancer properties of lamellarins. Mar Drugs, 2015; 13(3):1105-23. DOI:10.3390/md13031105

45. Cavalcanti BC, Júnior HVN, Seleghim MHR, Berlinck RGS, Cunha GMA, Moraes MO, et al. Cytotoxic and genotoxic effects of tambjamine D, an alkaloid isolated from the nudibranch Tambja eliora, on Chinese hamster lung fibroblasts. Chem Biol Interact, 2008; 174(3):155-62. DOI:10.1016/j.cbi.2008.05.029

46. Martinez De Pinillos Bayona A, Mroz P, Thunshelle C, Hamblin MR. Design features for optimization of tetrapyrrole macrocycles as antimicrobial and anticancer photosensitizers. Chem Biol Drug Des, 2017; 89(2):192-206. DOI:10.1111/cbdd.12792

47. Koníčková R, Vaňková K, Vaníková J, Vánová K, Muchová L, Subhanová I, et al. Anti-cancer effects of blue-green alga Spirulina platensis, a natural source of bilirubin-like tetrapyrrolic compounds. Ann Hepatol, 2014; 13(2):273-83. DOI:10.1016/s1665-2681(19)30891-9

48. Wang P, Karg CA, Frey N, Frädrich J, Vollmar AM, Moser S. Phyllobilins as a challenging diverse natural product class: Exploration of pharmacological activities. Arch Pharm, 2021; 354(10):2100061. DOI:10.1002/ardp.202100061

49. Teo RD, Hwang JY, Termini J, Gross Z, Gray HB. Fighting Cancer with Corroles. Chem Rev, 2017; 117(4):2711-29.

DOI:10.1021/acs.chemrev.6b00400

50. Xie A-N, Zhang Z, Wang H-H, Ali A, Zhang D$\mathrm{X}$, Wang $\mathrm{H}$, et al. DNA-binding, photocleavage and anti-cancer activity of tin(IV) corrole. J Porphyr Phthalocyanines, 2018; 22(09n10):73950. DOI:10.1142/s1088424618500256

51. Batinic-Haberle I, Tovmasyan A, Huang Z, Duan W, Du L, Siamakpour-Reihani S, et al. $\mathrm{H}(2) \mathrm{O}(2)-$ Driven Anticancer Activity of Mn Porphyrins and the Underlying Molecular Pathways. Oxid Med Cell Longev, 2021; 2021:6653790-. DOI:10.1155/2021/6653790

52. Benov L, Craik J, Batinic-Haberle I. The Potential of $\mathrm{Zn}$ (II) N-Alkylpyridylporphyrins for Anticancer Therapy. Anticancer Agents Med Chem, 2011; 11(2):233-41. DOI: $10.2174 / 187152011795255975$

53. Tovmasyan A, Bueno-Janice JC, Jaramillo MC, Sampaio RS, Reboucas JS, Kyui N, et al. Radiation-Mediated Tumor Growth Inhibition Is Significantly Enhanced with Redox-Active Compounds That Cycle with Ascorbate. Antioxid Redox Signal, 2018; 29(13):1196-214. DOI:10.1089/ars.2017.7218

54. Batinic-Haberle I, Tovmasyan A, Spasojevic I. Mn Porphyrin-Based Redox-Active Drugs: Differential Effects as Cancer Therapeutics and Protectors of Normal Tissue Against Oxidative 
Injury. Antioxid Redox Signal, 2018; 29(16):1691-724. DOI:10.1089/ars.2017.7453

55. Pegklidou K, Papastavrou N, Gkizis P, Komiotis D, Balzarini J, Nicolaou I. N-substituted Pyrrolebased Scaffolds as Potential Anticancer and Antiviral Lead Structures. Medicinal Chemistry, 2015; 11(6):602-8. DOI:10.2174/1573406411666150313161225

56. Ghorab MM, Ragab FA, Heiba HI, Youssef HA, El-Gazzar MG. Synthesis of novel pyrrole and pyrrolo[2,3-d]pyrimidine derivatives bearing sulfonamide moiety for evaluation as anticancer and radiosensitizing agents. Bioorg Med Chem Lett, $\quad 2010 ; \quad 20(21): 6316-20$. DOI:10.1016/j.bmcl.2010.08.005

57. Shamsuzzaman, Siddiqui T, Alam MG, Dar AM. Synthesis, characterization and anticancer studies of new steroidal oxadiazole, pyrrole and pyrazole derivatives. J Saudi Chem Soc, 2015; 19(4):38791. DOI:10.1016/j.jscs.2012.04.009

58. Boichuk S, Galembikova A, Syuzov K, Dunaev P, Bikinieva F, Aukhadieva A, et al. The Design, Synthesis, and Biological Activities of PyrroleBased Carboxamides: The Novel Tubulin Inhibitors Targeting the Colchicine-Binding Site. Molecules (Basel, Switzerland), 2021; 26(19):5780. DOI:10.3390/molecules26195780

59. Hura N, Sawant AV, Kumari A, Guchhait SK, Panda D. Combretastatin-Inspired Heterocycles as Antitubulin Anticancer Agents. ACS Omega, 2018; 3(8):9754-69. DOI:10.1021/acsomega.8b00996

60. Banwell MG, Hamel E, Hockless DCR, VerdierPinard P, Willis AC, Wong DJ. 4,5-Diaryl-1Hpyrrole-2-carboxylates as combretastatin A4/lamellarin T hybrids: Synthesis and evaluation as anti-mitotic and cytotoxic agents. Bioorg Med Chem, 2006; 14(13):4627-38. DOI:10.1016/j.bmc.2006.02.018

61. Jung E-K, Leung E, Barker D. Synthesis and biological activity of pyrrole analogues of combretastatin A-4. Bioorg Med Chem Lett, 2016; 26(13):3001-5. DOI:10.1016/j.bmcl.2016.05.026

62. Boichuk S, Galembikova A, Zykova S, Ramazanov B, Khusnutdinov R, Dunaev P, et al. Ethyl-2-amino-pyrrole-3-carboxylates are novel potent anticancer agents that affect tubulin polymerization, induce G2/M cell-cycle arrest, and effectively inhibit soft tissue cancer cell growth in vitro. Anticancer Drugs, 2016; 27(7):620-34.

DOI: $10.1097 /$ cad.0000000000000372

63. Spanò V, Rocca R, Barreca M, Giallombardo D, Montalbano A, Carbone A, et al. Pyrrolo[2',3':3,4]cyclohepta[1,2-d][1,2]oxazoles, a New Class of Antimitotic Agents Active against Multiple Malignant Cell Types. J Med Chem,
2020; 63(20):12023-42.

DOI:10.1021/acs.jmedchem.0c01315

64. Kilic-Kurt Z, Bakar-Ates F, Aka Y, Kutuk O. Design, synthesis and in vitro apoptotic mechanism of novel pyrrolopyrimidine derivatives. Bioorg Chem, 2019; 83:511-9. DOI:10.1016/j.bioorg.2018.10.060

65. Zhu T, Shen S, Lu Q, Ye X, Ding W, Chen R, et al. Design and synthesis of novel N()-substituted thiosemicarbazones bearing a pyrrole unit as potential anticancer agents. Oncol Lett, 2017; 13(6):4493-500. DOI:10.3892/ol.2017.5995

66. Li Z, Luo M, Cai B, Wu L, Huang M, Haroon Ur $\mathrm{R}$, et al. Design, synthesis and biological evaluation of matrine derivatives as potential anticancer agents. Bioorg Med Chem Lett, 2018; 28(4):677-83. DOI:10.1016/j.bmcl.2018.01.017

67. Fatahala SS, Mohamed MS, Youns M, Abd-El Hameed RH. Synthesis and Evaluation of Cytotoxic Activity of Some Pyrroles and Fused Pyrroles. Anticancer Agents Med Chem, 2017; 17(7):1014-25.

DOI:10.2174/1871520617666170102152928

68. Bavadi M, Niknam K, Shahraki O. Novel pyrrole derivatives bearing sulfonamide groups: Synthesis in vitro cytotoxicity evaluation, molecular docking and DFT study. J Mol Struct, 2017; 1146:242-53.

DOI:10.1016/j.molstruc.2017.06.003

69. Thiriveedhi A, Nadh RV, Srinivasu N, Bobde Y, Ghosh B, Sekhar KVGC. Design, synthesis and anti-tumour activity of new pyrimidine-pyrrole appended triazoles. Toxicol In Vitro, 2019; 60:8796. DOI:10.1016/j.tiv.2019.05.009

70. Dutour R, Poirier D. Inhibitors of cytochrome P450 (CYP) 1B1. Eur J Med Chem, 2017; 135:296-306. DOI:10.1016/j.ejmech.2017.04.042

71. Sonawane VR, Siddique MUM, Gatchie L, Williams IS, Bharate SB, Jayaprakash V, et al. CYP enzymes, expressed within live human suspension cells, are superior to widely-used microsomal enzymes in identifying potent CYP1A1/CYP1B1 inhibitors: Identification of quinazolinones as CYP1A1/CYP1B1 inhibitors that efficiently reverse $\mathrm{B}[\mathrm{a}] \mathrm{P}$ toxicity and cisplatin resistance. Eur J Pharm Sci, 2019; 131:177-94. DOI:10.1016/j.ejps.2019.02.016

72. Williams IS, Joshi P, Gatchie L, Sharma M, Satti NK, Vishwakarma RA, et al. Synthesis and biological evaluation of pyrrole-based chalcones as CYP1 enzyme inhibitors, for possible prevention of cancer and overcoming cisplatin resistance. Bioorg Med Chem Lett, 2017; 27(16):3683-7. DOI:10.1016/j.bmcl.2017.07.010

73. Suraweera A, O'Byrne KJ, Richard DJ. Combination Therapy With Histone Deacetylase Inhibitors (HDACi) for the Treatment of Cancer: Achieving the Full Therapeutic Potential of 
HDACi. Front Oncol, 2018; 8:92-. DOI:10.3389/fonc.2018.00092

74. Singh A, Patel VK, Rajak H. Appraisal of pyrrole as connecting unit in hydroxamic acid based histone deacetylase inhibitors: Synthesis, anticancer evaluation and molecular docking studies. J Mol Struct, 2021; 1240:130590. DOI:10.1016/j.molstruc.2021.130590

75. Geretto M, Ponassi M, Casale M, Pulliero A, Cafeo G, Malagreca F, et al. A novel calix[4]pyrrole derivative as a potential anticancer agent that forms genotoxic adducts with DNA. Sci Rep, 2018; 8(1):11075-. DOI:10.1038/s41598018-29314-9

76. Santoso M, Fadlan A, Fahmi MRG, Rahmayanti A. Synthesis and in vitro cytotoxicity evaluation of isatin-pyrrole derivatives against HepG2 cell line. Open Chem, 2021; 19(1):199-204. DOI:10.1515/chem-2021-0023

77. Liu J-H, Zhang R-R, Peng X-R, Ding Z-T, Qiu MH. Lepipyrrolins A-B, two new dimeric pyrrole 2carbaldehyde alkaloids from the tubers of Lepidium meyenii. Bioorg Chem, 2021; 112:104834. DOI:10.1016/j.bioorg.2021.104834

78. Khalilpour A, Asghari S. Synthesis, characterization and evaluation of cytotoxic and antioxidant activities of dihydropyrimidone substituted pyrrole derivatives. Med Chem Res, 2017; 27(1):15-22. DOI:10.1007/s00044-0172041-4

79. Ji J, Sajjad F, You Q, Xing D, Fan H, Reddy AGK, et al. Synthesis and biological evaluation of substituted pyrrolidines and pyrroles as potential anticancer agents. Arch Pharm, 2020; 353(12):2000136. DOI:10.1002/ardp.202000136

80. Mbugua S, Sibuyi N, Njenda L, Odhiambo R, Wandiga S, Meyer M, et al. New Palladium(II) and Platinum(II) Complexes Based on Pyrrole Schiff Bases: Synthesis, Characterization, Xray Structure, and Anticancer Activity. ACS Omega, 2020; 5(25):14942-54.

DOI:10.1021/acsomega.0c00360

81. Popova EA, Protas AV, Trifonov RE. Tetrazole Derivatives as Promising Anticancer Agents. Anticancer Agents Med Chem, 2018; 17(14):1856-68.

DOI:10.2174/1871520617666170327143148

82. Zhang M, Ding Y, Qin H-X, Xu Z-G, Lan H-T, Yang D-L, et al. One-pot synthesis of substituted pyrrole-imidazole derivatives with anticancer activity. Mol Divers, 2019; 24(4):1177-84. DOI:10.1007/s11030-019-09982-z

83. Rasal NK, Sonawane RB, Jagtap SV. Potential 2,4-dimethyl-1H-pyrrole-3-carboxamide bearing benzimidazole template: Design, synthesis, in vitro anticancer and in silico ADME study. Bioorg Chem, 2020; 97:103660. DOI:10.1016/j.bioorg.2020.103660
84. Toubia I, Nguyen C, Diring S, Ali LMA, Larue L, Aoun R, et al. Synthesis and Anticancer Activity of Gold Porphyrin Linked to Malonate Diamine Platinum Complexes. Inorg Chem, 2019; 58(18):12395-406.

DOI:10.1021/acs.inorgchem.9b01981

85. Zhan X-P, Lan L, Wang S, Zhao K, Xin Y-X, Qi $\mathrm{Q}$, et al. Synthesis and Anticancer Activity of 3(Substituted Aroyl)-4-(3,4,5-trimethoxyphenyl)1H-pyrrole Derivatives. Chem Biodivers, 2017; 14(2):e1600219. DOI:10.1002/cbdv.201600219 